\title{
Research Initiative on Bilingual Teaching Mode of Sino- Foreign Project of International Hotel Management A Case Study of International Hotel Management Teaching in Yunnan Open University
}

\author{
Zeng Yan \\ Culture and Tourism Department, Yunnan Open University, Kunming, Yunnan, China \\ 171908@sina.com
}

\begin{abstract}
This paper focuses on a sample of international hotel management class in Yunnan Open University, to analyze the essentialness and significance of initializing bilingual teaching there. This paper also tries to figure out the obstacles facing and effective modes can be used in teaching process, which bases on the experiences have got in Sino-foreign cooperation and knowledge about current strategies using in foreign countries, and also comply with the aims and features of bilingual teaching.

Index Terms - Sino-foreign cooperation, significance, obstacle, effective mode of bilingual teaching
\end{abstract}

\section{Introduction}

Along with economic globalization, the rapid development of Internet technology and international education, China need large number of high quality talents, who proficient in gaining professional knowledge, communicating in foreign language, acquainting the international market operation rules, and adapting to the international competition. As the international language, English becomes more and more important.

Today, international exchanges are in high frequency. Tourism and hotel management is affected by the high-speed development as many other majors-financial, legal, etc. From the current development of global economic, hospitality industry is more and more important and tends to be stable [1]. In this context, according to the practical needs of society, Yunnan Open University carried out a Sino-foreign Project of international hotel management with the Australia Chisholm Institute of TAFE by research and planning. This paper attempts to explore the practical bilingual teaching mode according to the teaching practice, the goal of the bilingual teaching and the professional characteristics of the courses.

\section{Domestic and Foreign Bilingual Teaching Mode}

\section{A. Foreign Bilingual Teaching Mode}

Foreign bilingual teaching mode mainly includes the immersion bilingual teaching; transitional bilingual teaching and maintenance bilingual teaching. Immersion bilingual teaching compares language to swimming. It puts students into the foreign language environment and let them choking, struggling in the language water until they learn foreign language well. This mode can make students drowning in the target language, make them mastering and using the foreign language as soon as possible. Teachers use the target language teaching not only to teach language knowledge, but also to demonstrate professional knowledge. That is to say the target language is both learning content and learning tool. Immersion bilingual teaching mode promotes the transformation from traditional isolated bilingual teaching to language and professional combined bilingual teaching. The implement of this kind of teaching mode is not only beneficial for students improving the level of language, but also advancing professional level [2]. It requires teachers master the language and professional knowledge. While the transitional bilingual teaching mode allows students to use their own language from the initial to longer time, and allows teachers to use the students' mother tongue teaching knowledge and skills until the students grasp the target language well. The school must use the target language step by step, and then increase the adapted proportion of target language gradually. Maintenance Bilingual teaching is an education that the mainstream society allows the students to use minority language so that ethnic language can be protected and prevented to disappear.

\section{B. Domestic Bilingual Teaching Mode}

Domestic bilingual teaching includes three sorts of mode, half bilingual teaching, mixed bilingual teaching and full bilingual teaching. In half bilingual teaching mode, teachers use foreign didactical materials but teaching in Chinese. This pattern is lower level teaching. So it has many practical problems. For example, how to help students to learn? How to use foreign didactical materials? How to design the whole course? It's hard to properly distinguish the extent or boundary between bilingual teaching and professional field teaching from analysis of teaching effect.

In mixed bilingual teaching mode, teachers use foreign didactical materials teaching in mixed language, Chinese and foreign language. But the teaching progress in class is much slow than the generally mode by using two languages same time. So the key of this mode is how to effectively design the teaching content in class so as to ensure teachers can achieve the teaching goal of anticipated task in effective time. And how to assign the proportion between Chinese and foreign languages is more importance.

Teachers in full bilingual teaching mode use foreign 
didactical materials only in the professional field and teach students in foreign language directly. Students study, accept professional knowledge and skills in foreign language. This is a high level bilingual teaching mode which requires higher abilities in teaching and learning for teachers and students respectively.

\section{The Difficulty of Bilingual Teaching Practice in International Hotel Management}

The bilingual teaching practice in International hotel management class is still in initial stage in the Sino-foreign project. How to switch and use two languages, effectively design the content of class teaching and realize the goal of the curriculum in the effective time is the most important problem at present. In initial exploration of teaching practice, the teachers can't teach in full English, only do half English or mixed bilingual teaching. So how to grasp the proportion in two languages is a problem. Although students have study English listening, speaking, reading, writing and various types of English courses in the first year, study the professional knowledge in English is still a big challenge for those students with lower ability of English. They need not only to overcome language barriers through mastering a large vocabulary, read professional materials, but also to learn intercultural thinking based on mastering professional content, solve professional problems, use English to express ideas and communicate before learning professional knowledge. How to combine the reality and characteristics of the students, plan and implement bilingual teaching. Neither turns the bilingual courses into professional English courses, nor takes the foreign language as burden in teaching. The key point is school, teachers and students' efforts to explore the best intersection of professional knowledge teaching, ability cultivation for students and advance in language level.

\section{The Progressive and Cooperative Bilingual Teaching Mode Structure}

At present, many universities have implemented bilingual teaching and formed their own teaching mode gradually. However, adult education needs to explore a characteristic bilingual teaching mode suit for itself. The progressive and cooperative bilingual teaching mode makes some modifications based on immersion bilingual teaching mode and combines the actual situation of practices in international hotel management class. The teaching process of this mode reflect the professional skills, practicability, and infotainment which can arouse the enthusiasm of teachers and students, especially embody the students' main position in the teaching and teachers' guiding role, finally meet the adult education requirements. According to the abilities issuer of teachers and students mentioning in front, especially the students' English level uneven problems, bilingual teaching progress must be a multi-level, step-by-step process.

In following sections, the paper will demonstrated the structure of progressive and cooperative bilingual teaching mode based on the teaching phase in different semesters and 6 elements of teaching -- teaching material, teaching process, courseware, communication, operation/writing work and examination.

\section{A. The first phase: Transition}

This phase will be applied in the first semester. In this phase, Chinese is the main medium language in all the teaching content. Using English to explain, sum up and summarize the professional terminology, basic theory and core ideas from "training package" (some teaching materials) providing from partners (the Australia Chisholm Institute). Part of English materials from "training package" will be imported and using full Chinese materials as accessory. The proportion of English is $20 \%$ in one course. The Courseware designed both in English and Chinese. Students and teachers communicate mainly in Chinese. English is using as the auxiliary tool. In question and answer process, the language should keep consistent between teacher and students, so as in homework and examination. The first phase teaching mode can effectively solve the lower English levels issue for students, reduce the students' difficulties of learning the professional knowledge coursed by limited comprehension of professional knowledge in English context.

\section{B. The second phase: Extension}

This phase will be applied in the second semester. In this phase, Chinese is still the main medium language in teaching. And English's proportion will be increased. It will include not only professional terminology, basic theory and core ideas, but also the professional system knowledge, English cases and some training activities from "training package" so that to make teaching more intuitionistic and vivid. The Courseware will be designed in English. Teacher and students will use the bilingual teaching materials and some full English materials from "training package" as accessory materials. The proportion of English in one course is 30\%. Students and teachers communicate mainly in Chinese and English as the auxiliary tool. English and Chinese will mix used in question and answer, homework and examination. The extension phase teaching mode use professional keywords as the breakthrough point and clear up the professional knowledge in Chinese distinctly. So students can form the thinking mode in bilingual context based on professional terminology, basic concepts and other professional core content, and not be affected in learning breadth and depth by lower English level issue.

\section{The third phase: Conversion}

This phase will be applied in the third semester. In this phase, teachers use English as the main medium language in teaching and alternately make code-switching between English and Chinese. Code-switching is a phenomenon of using in English and Chinese alternately. It often appears in words, phrases, clauses, sentences or sentence form, so people often use it as a linguistic strategy to achieve some communicative purposes [3]. Through language code-switching, professional course can permeate into the students' studying process. Teacher integrates language code-switching and the teaching activity, and builds up a big language environment in the continuous teaching [4]. In conversion phase teaching mode, 
teachers explain the course content switching between Chinese and English continuously. Teacher doesn't need to translate English in Chinese one by one, only need to adjust the proportion according to the students' acceptability. Especially in teaching special professional knowledge or theory, teacher should explain and describe in Chinese. The teaching material will be the full English from the "training package". The proportion of English teaching in one course is at least $50 \%$

( The accuracy proportion will accord the students real level ). The Courseware will be designed in English. Students and teachers communicate mainly in English and use Chinese as the auxiliary tool. Use English in question and answer process, but two languages in the homework and examination. Through the previous two phases, students have gained the langrage fundamentals knowledge and the bilingual learning experience. So in the third phase, students can adapt to consecutive language switching and convert Chinese thinking mode into English thinking mode flexibly.

\section{The fourth phase: Expansion}

This phase will be applied in fourth, fifth semesters. In this phase, teachers use English as the main medium language in teaching, make language code-switching in two languages, increase English proportion, expand extracurricular English materials and training activities in the teaching press to form the simulative work task and carry out the professional training. The teaching material is the full English coming from the "training package" and the proportion of English teaching in one course is $60 \%$. The Courseware will be designed in English. Students and teachers communicate mainly in English and use Chinese as the auxiliary tool. Question and answer, homework and examination are all in English. Through the fourth phase's teaching, students can gain the comprehension ability to professional knowledge in depth and breadth when they accomplish some cases and training activities in the simulative work task. Especially in the process of accomplishing goal in simulative work task, students can establish some important abilities. For example, form a crosscultural thinking way, solve professional problems, use English to express ideas, communicate in English, etc.

\section{E. The "cooperative" bilingual teaching mode}

In each of the above phase, the "progressive" bilingual teaching mode and "cooperative" bilingual teaching is both imported. "Cooperative" bilingual teaching is Chinese and foreign teachers co-teaching in class. In the Sino-foreign cooperative education project, there are foreign teachers coming to china to teach parts of the curriculum in each semester. From the teaching practical experience there are some problems in independent foreign teacher teaching. For example, the students cannot fully understand the language; it is difficult to obtain some professional knowledge under different background; the foreign teachers do not acquaint with students, etc. For the above problems, the foreign teacher teaching must have one or two Chinese teachers as assistant in each phase. They co-operated with each other but the responsibility of them must be divided. In this mode, foreign teachers is the main speaker, responsible for course design, teaching course, set the evaluation on teaching process and implement them. Chinese teachers are primarily responsible for providing explanation, translating, guiding classroom and extracurricular activities, coordination the communication between foreign teachers and students, and supervising the whole teaching process. The "cooperative " bilingual teaching mode parallels with the "progressive "bilingual teaching mode, provide more teaching exchange and discuss opportunities for bilateral teachers, ensure foreign teachers teaching smoothly, improve teaching quality and promote research and cooperation in bilateral teachers.

According to exploration and analysis in the progressive and cooperative bilingual teaching mode, the basic framework will be formed as Figure 1.



Fig.1. The Progressive and Cooperative Bilingual Teaching Mode Structure 


\section{Conclusion}

In the progressive and cooperative bilingual teaching mode, each phase from top to bottom will influence mutually. From the first phase to the fourth phase, each phase is the bases of the next phase and the teaching effect of previous phase will affect the progress of later phase. Of course, as the connection is close with two adjacent phases, the teaching in the next phase can make up the teaching issue of the previous phase if the effect of previous phase is not satisfied. From the fourth phase to the first phase, each phase plays supervision and inspection role in the previous phase so that we can adjust, make up the issue which affecting the teaching effect and improve, perfect in the next teaching round. In sum, the progressive and cooperative bilingual teaching mode is a iterative dynamic teaching mode. Its iterative dynamic characteristic guarantees its sustainable development.

\section{Acknowledgment}

Grateful thanks are due to many people who helped me with my teaching. My thanks, go to my dear colleagues: $\mathrm{Li}$ Liqiong, Jia Hongfeng, Wang Yuerong, who give me many helps and support and to my dear students, who give me so lovely teaching experience.

\section{References}

[1] Yu Jifeng, "Bilingual teaching of tourism subjects," Annals of tourism research, vol. S1, 2004, pp. 69-72.
[2] Wang Ying, "Bilingual education theory and practice -- a comparative study of Chinese and foreign bilingual education," Shanghai Education Publishing House, 2008, pp.167.

[3] Cai Mingde, Liu Zhentian, Liu Yubin, Song Min, Li Xiaomei, "Codeswitching -- new mode of bilingual teaching and education," Education Study, 2007, pp. 90.

[4] Li Xiaomei, "Importance should be attached to the code-switching in bilingual teaching," Chinese Higher Education Research, 2008.

[5] Cui Jing, "The analysis the relativity between social environment and bilingual teaching," Xinjiang social science forum, 2008.

[6] Du Xiangjun, "Classroom culture of bilingual education," Education Research., 2007.

[7] He Changyi, "Canadian Multicultural and bilingual teaching in the universities," Yunnan Higher Education Research, vol. 1, 1997.

[8] He Jiarong, Li Guishan, "Chinese bilingual teaching," Science Press, 2010.

[9] Huang Anyu, "Quality education in South Australia," Quality Education Reference, 2003.

[10] Huang Anyu, "The theory and practice of bilingual teaching research," Shanghai people's publishing house, China, 2011, pp.206.

[11] Sun Jia, "Quebec Canada "immersive" bilingual education research review," Journal of Hubei Adult Education Institute, 2009.

[12] Wang Ning, "The main courses of tourism discipline "bilingual" teaching mode and practice," Annals of tourism research, vol.S1, 2005.

[13] Wu Xiaoyan, "The studing and structure the bilingual teaching mode based on student occupation ability development," Higher Occupation Education, 2011, pp.73.

[14] Yang Lier, "Hotel management talents cultivation plan," Yunnan Radio TV University demonstrative specialty construction project, 2011.

[15] Yang Qi, "In University English teaching and bilingual teaching in comparative analysis," Higher Education Research., 2009.

[16] Zhao Yanzhi, "Chinese foreign cooperation in running schools -governance and development," Northeast University of Finance and Economics press, 2010. 